\title{
PERANCANGAN SISTEM MANAJEMEN TOKO BAJU RUMAH KAOS BERBASIS JAVA
}

\author{
Mochammad Abdul Rochim ${ }^{1}$, Tri Yani Akhirina², Asri Budiarto ${ }^{3}$ \\ Program Studi Teknik Informatika, Fakultas Teknik dan Ilmu Komputer, \\ Universitas Indraprasta PGRI \\ Jalan Raya Tengah No 80, Kelurahan Gedong, Pasar Rebo, Jakarta Timur \\ rochim.edu@gmail.com¹, azizahputriku@gmail.com ${ }^{2}$, asribudiarto@gmail.com ${ }^{3}$
}

\begin{abstract}
Abstrak
Toko Baju Rumah Kaos memulai kegiatan usaha di bidang penjualan kaos saja pada tahun 2011 dengan tujuan awal untuk dapat memberikan alternative pilihan kaos murah tapi tetap trendi. Searah dengan perkembangan tren pakaian, Toko Baju Rumah Kaos pada tahun 2012 mulai menambah koleksinya berupa celana, kemeja, dan juga jaket.Sementara itu pengelolaan data barang yang berada di toko baju Rumah Kaos bersifat tradisional yaitu dilakukan secara manual. Pengelolaan data barang yang tradisional tersebut dapat menghambat proses administrasi toko, karena untuk memperoleh data dilakukan dengan memeriksa dari sekian banyak barang yang ada, sehingga memerlukan banyak waktu. Tujuan dari penelitian ini adalah membuat perancangan sistem manajemen toko untuk memudahkan dalam pengelolaan toko secara komputasi. Adapun perancangan aplikasi menggunakan Diagram Alir Data (DAD) dengan aplikasi pendukun yaitu Netbeans IDE 8.2 dan MySQL untuk perancangan basis datanya.
\end{abstract}

Kata Kunci: Manajemen, Toko, Java, MySQL, DAD

\begin{abstract}
Rumah Kaos Clothing Store started business activities in the field of T-shirt sales only in 2011 with the initial goal to be able to provide alternative options of cheap but still trendy T-shirts. In line with the development of clothing trends, Rumah Kaos Clothing Store in 2012 began to add to its collection in the form of pants, shirts, and jackets. Meanwhile, the management of goods data located in rumah kaos clothing store is traditional, which is done manually. Traditional goods data management can hamper the store administration process, because to obtain data is done by checking from many existing items, so it takes a lot of time. The purpose of this research is to design a store management system to facilitate the management of stores computationally. The application design uses Data Flow Diagram (DAD) with supporting applications namely Netbeans IDE 8.2 and MySQL for database design.
\end{abstract}

Keywords: Management, Store, Java, MySQL, DAD

\section{PENDAHULUAN}

Sistem informasi mencakup sejuamlah komponen (manusia, komputer dan prosedur kerja) ada suatu proses (data menjadi informasi) dan dimaksudkan untuk mencapai suatu sasaran atau tujuan (Kadir, 2014). Sistem informasi saat ini berkembang begitu pesat. Berbagai aplikasi sistem informasi memungkinkan pemrosesan data dan laporan dengan cepat. Ragam penggunaan teknologi mengakibatkan seluruh bidang kehidupan berubah tidak terkecuali sebuah toko. Perancangan sistem adalah sebuah kegiatan merancang dan menentukan cara mengolah sistem informasi dari hasil analisa sistem sehingga dapat memenuhi kebutuhan dari pengguna termasuk diantaranya perancangan user interface, data dan aktivitas proses (O'Brien dan Marakas, 2013). Sistem merupakan sekelompok elemen-elemen yang saling berhubungan atau berinteraksi hingga membentuk satu-persatuan, dan bekerja sama untuk mencapai tujuan bersama dengan menerima input (masukan) sehingga menghasilkan output (keluaran) dalam prosestransformasi yang teratur. (Indrajani, 2011). Sedangkan menurut Stoner dan Freeman (Safroni, 2012), "Manajemen adalah proses perencanaan, pengorganisasian, kepemimpinan, dan pengendalian upaya anggota organisasi dan proses penggunaan semua sumber daya organisasi untuk tercapainya tujuan organisasi yang telah ditetapkan". Peran manajemen saat ini dan di masa datang setiap saat dituntut untuk mengetahui perkembangan informasi yang dapat diakses dari media telekomunikasi. Hal ini merupakan tantangan bagi pengelola toko untuk bersikap dan bertindak. Hal tersebut yang menjadi 
latar belakang untuk merancang dan membuat sistem informasi manajemen toko rumah kaos jakarta berbasis Java Netbeans. Java merupakan salah satu dari sekian banyak bahasa pemograman yang dapat dijalankan di berbagai sistem operasi termasuk telepon genggam" (Nofriadi, 2015). Hasil yang diharapkan dari pembuatan sistem informasi manajemen ini, dapat menyampaikan informasi untuk pihak pemilik toko dan pembeli yang membutuhkan data barang melalui komputer yang sudah terprogram dengan aplikasi desktop.

\section{PENELITIAN RELEVAN}

Sebagai acuan dalam penelitian peneliti juga merasa perlu mempelajari lebih dalam tentang apa yang akan diteliti, penelitian-penelitian yang sudah dilakukan terdulu menjadi reverensi peneliti agar isi dari penelitian ini lebih bermanfaat dan aktual, Adapun penelitian yang menjadi reverensi peneliti untuk mengangkat topik penelitian ini adalah sebagai berikut :

Penelitian (Hasyim, Faisal Ibnu, 2012) dengan judul "Sistem Informasi Penjualan Pakaian Jadi Pada Distro Blindwear Bandung". Distro Blindwear Bandung merupakan perusahaan yang bergerak dalam bidang produksi dan penjualan pakajan seperti penjualan baju, jaket, topi dan asesoris lainnya. Namun dalam hal proses penjualan pada distro ini masih dilakukan secara manual, seperti dalam pembuatan data barang, permintaan barang, transaksi penjualan dan laporan penjualan masih dilakukan dengan mencatat secara manual pada faktur penjualan dan buku kas, hál ini terjadi karena pada distro Blindwear ini belum mempunyai sebuah sistem informasi yang mendukung dalam proses pejualan barang sehingga menyebabkan tidak efektif dan efisiennya kinerja perusahaan. Maka untuk dapat meningkatkan kinerja perusahaan diperlukan suatu media informasi.

Penelitian (Pratini, Anggie, 2017) tentang "Perancangan Sistem Informasi Laporan Keuangan Pada Distro Viloci Pontianak". Distro Viloci membutuhkan sekali adanya suatu sistem informasi akuntansi yang telah terkomputerisasi. Untuk itulah penulis mencoba membuat tugas akhir mengenai sistem laporan keuangan pada Distro Viloci yang sampai saat ini belum terkomputerisasi. Penerapan sistem informasi akuntansi ini merupakan solusi terbaik untuk memecahkan permasalahan-permasalahan yang ada pada toko tersebut, serta dengan sistem yang terkomputerisasi dapat tercapai suatu kegiatan yang efektif dan efisien dalam menunjang aktifitas pada toko tersebut.

Penelitian (Wulandari, Anggreani P., dkk, 2018) tentang "Sistem Informasi Penjualan Pakaian Pada Butik Aulia". Tujuan dari penelitian ini adalah membangun Sistem Informasi untuk memberikan kemudahan kepada butik Aulia dalam tata kelola administrasi sehingga pada transaksi penjualan pakaian dapat terkontrol dengan baik.

Penelitian (Ali, 2019) tentang "Rancang Bangun Aplikasi Penjualan Barang Berbasis Java Programming". Aplikasi penjualan ini dibuat dalam bentuk sederhana yang dapat digunakan dengan mudah.

(Herlina, 2016) telah melakukan penelitian tentang "Sistem Informasi Penjualan Pada Toko Busana Qiand Collection Berbasis Desktop". Maksud dari penelitian ini adalah untuk membantu user dalam mengolah data atau informasi

\section{METODE PENELITIAN}

Metode pengumpulan dan merupakan aspek yang berperan penting dalam kelancaran perancangan sistem data yang diperlukan berupa data inventori dan data karyawan untuk Pengembanagan Sistem Manajemen Toko di Rumah Kaos Jakarta. Metode pengumpulan data yang dilakukan penulis untuk mendapatkan data-data dan informasi untuk mendukung penyempurnaan hasil dari penelitian ini antara lain:

\section{Observasi}

Kegiatan observasi meliputi melakukan pencatatan secara sistematik kejadian-kejadian, perilaku dan hal-hal lain yang diperlukan dalam mendukung penelitian yang sedang dilakukan. Pada tahap awal, peneliti mengumpulkan data atau informasi dari bagian kasir dan gudang di toko baju Rumah Kaos. Tahap selanjutnya menyempitkan data atau informasi yang diperlukan sehingga peneliti dapat melakukan pola perilaku dan hubungan yang terus menerus terjadi. 
2. Wawancara

Wawancara dimulai dengan mengemukakan topik yang umum untuk membantu peneliti memahami perspektif makna yang diwawancarai sesuai dengan asumsi dasar penelitian berupa jawaban yang diberikan harus membeberkan perspektif yang diteliti.

3. Kepustakaan

Metode kepustakaan adalah metode penelitian yang menekankan pada pustaka sebagai suatu objek studi pustaka pada hakekatnya merupakan hasil olah budi manusia dalam bentuk karya tulis (literacy) guna menuangkan gagasan/ide/pandangan hidupnya dari seseorang ataupun sekelompok orang. Pada metode ini penulis melakukan pencarian pustaka melalui internet dan juga buku-buku yang penulis baca.

HASIL DAN PEMBAHASAN

Diagram Alir Data (DAD) Sistem Yang Diusulkan

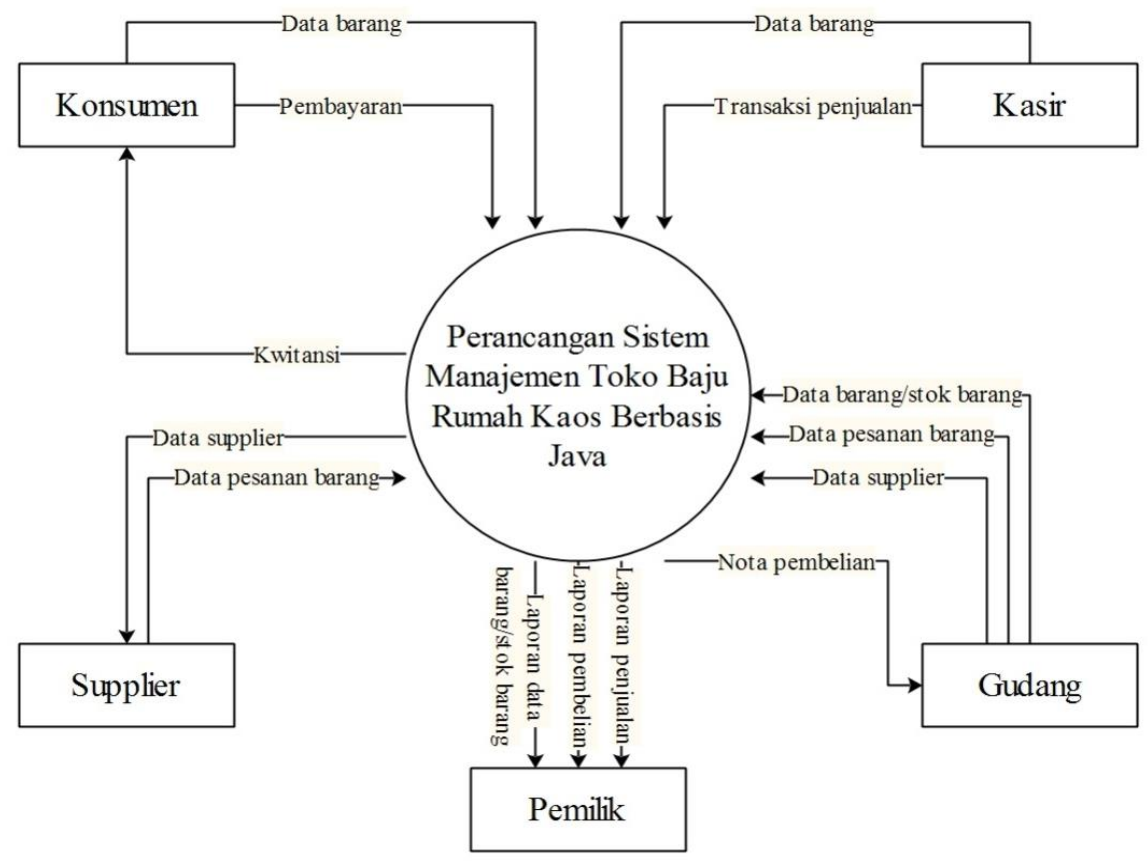

Gambar 1. Diagram Alir Data (DAD) Sistem Yang Diusulkan

\section{Normalisasi Bentuk Ke-1 (1NF) Sistem Yang Diusulkan}

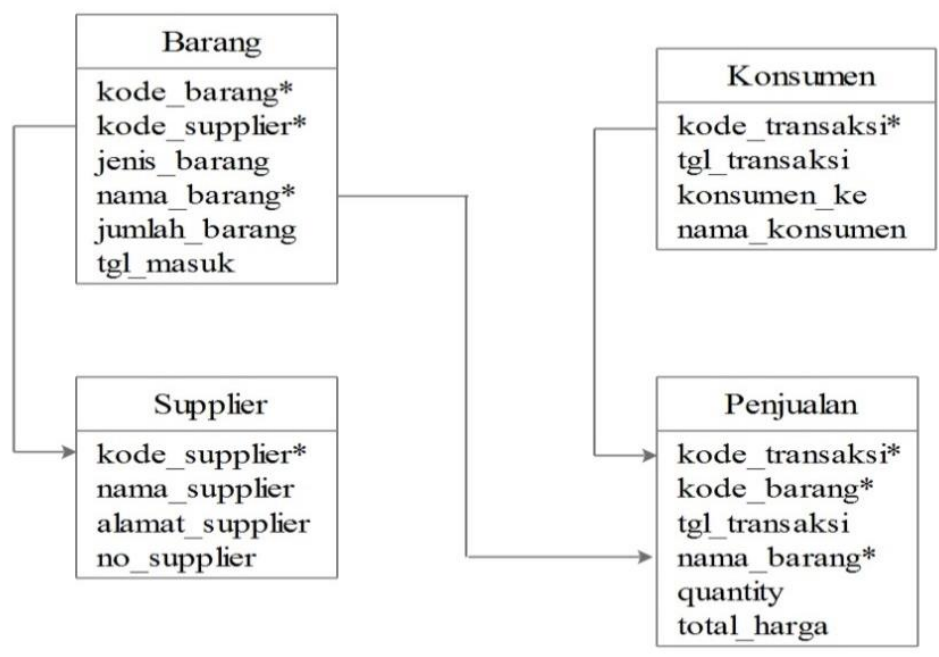


Tampilan Layar

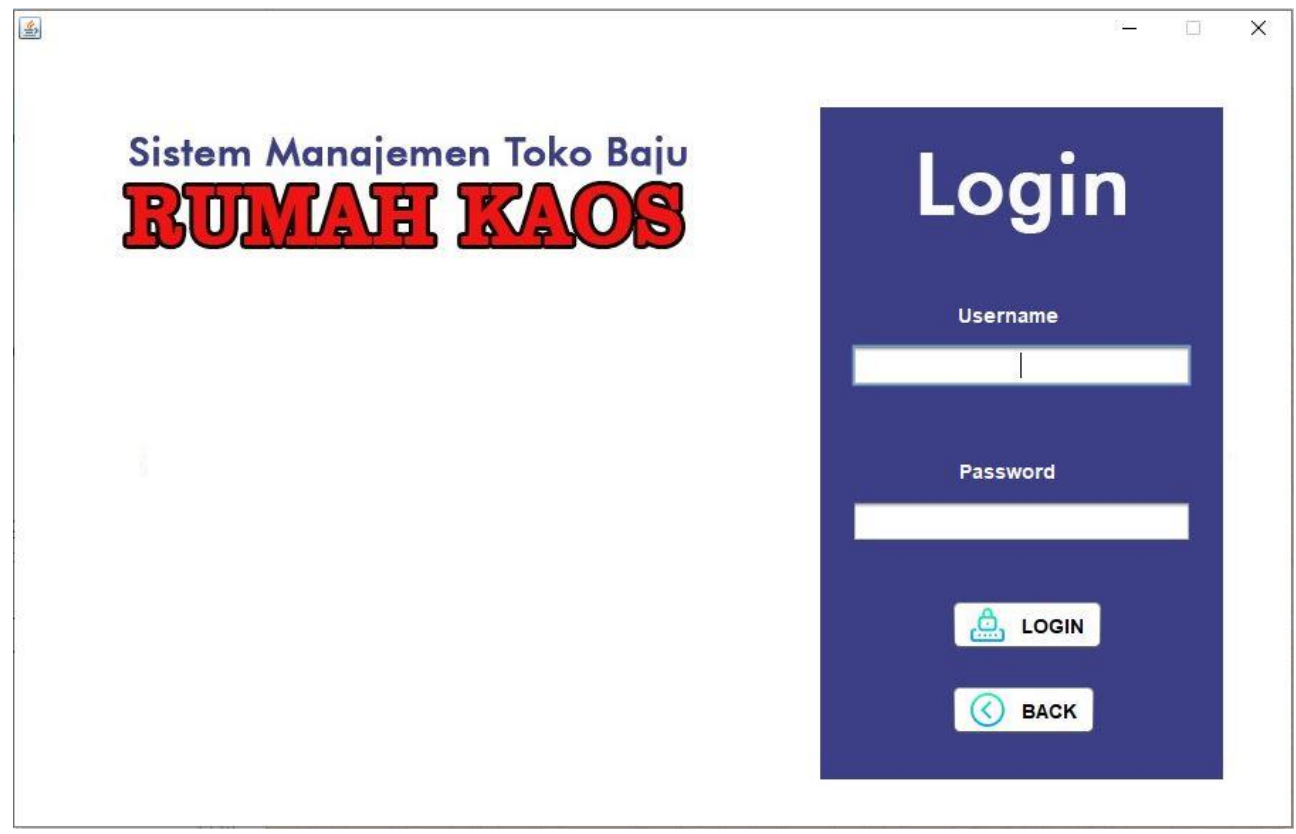

Gambar 3. Tampilan Layar Halaman Login

Pada From menu login ini muncul diawal saat pengoprasian program. Pengguna memiliki dua opsi pengoperasian, bisa login menggunakan user admin atau kasir sesuai keperluan. Ketika pengguna mengklik salah satu tombol maka akan dialikan ke halaman login. Pengguna mengisikan username dan password, jika data sesuai makan pengguna dapat melanjutkan ke menu utama.

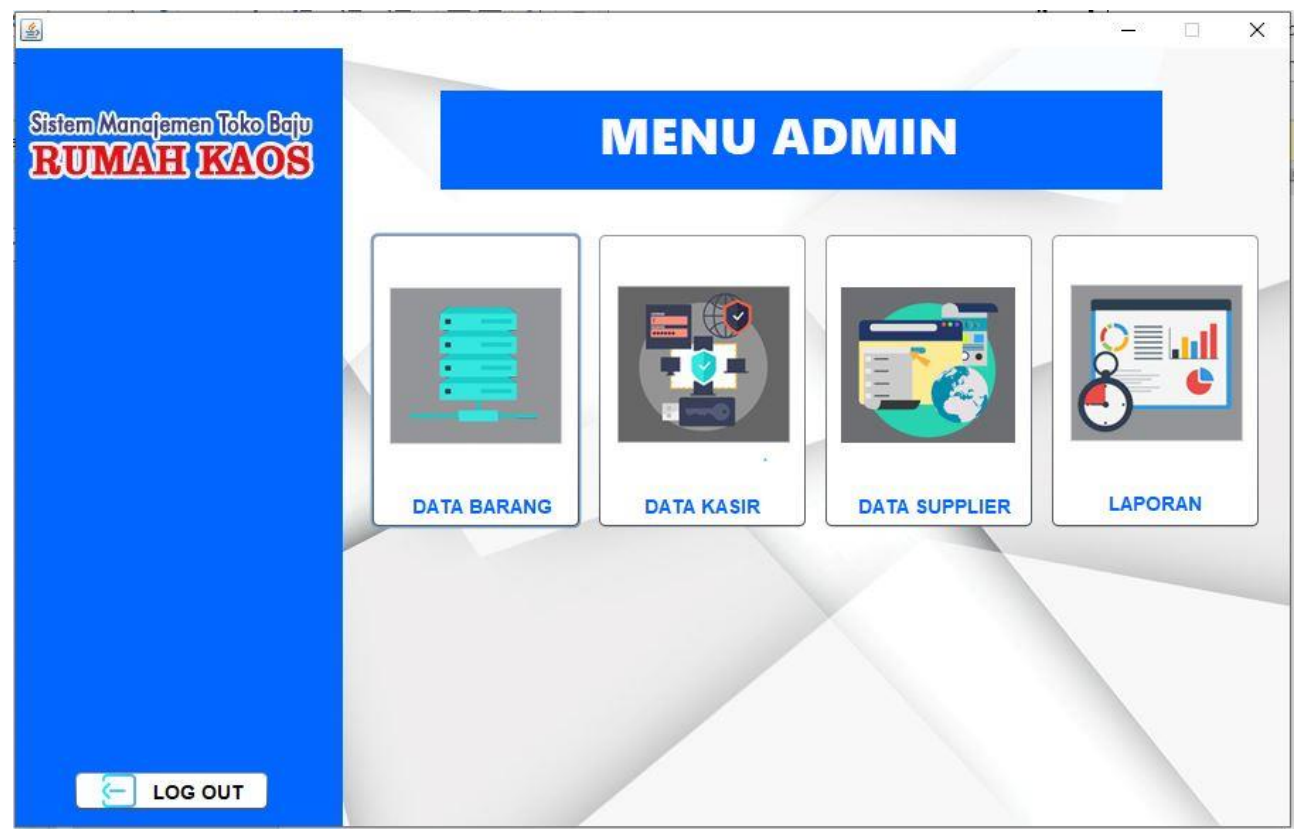

Gambar 5. Tampilan Layar Menu Admin

Aplikasi ini memiliki dua menu utama yaitu menu utama sebagi admin dan menu utama sebagai kasir. Pada tampilan menu utama admin terdapat beberapa menu yang akan menampilkan form data barang, form data kasir, form data supplier, dan halaman laporan. 


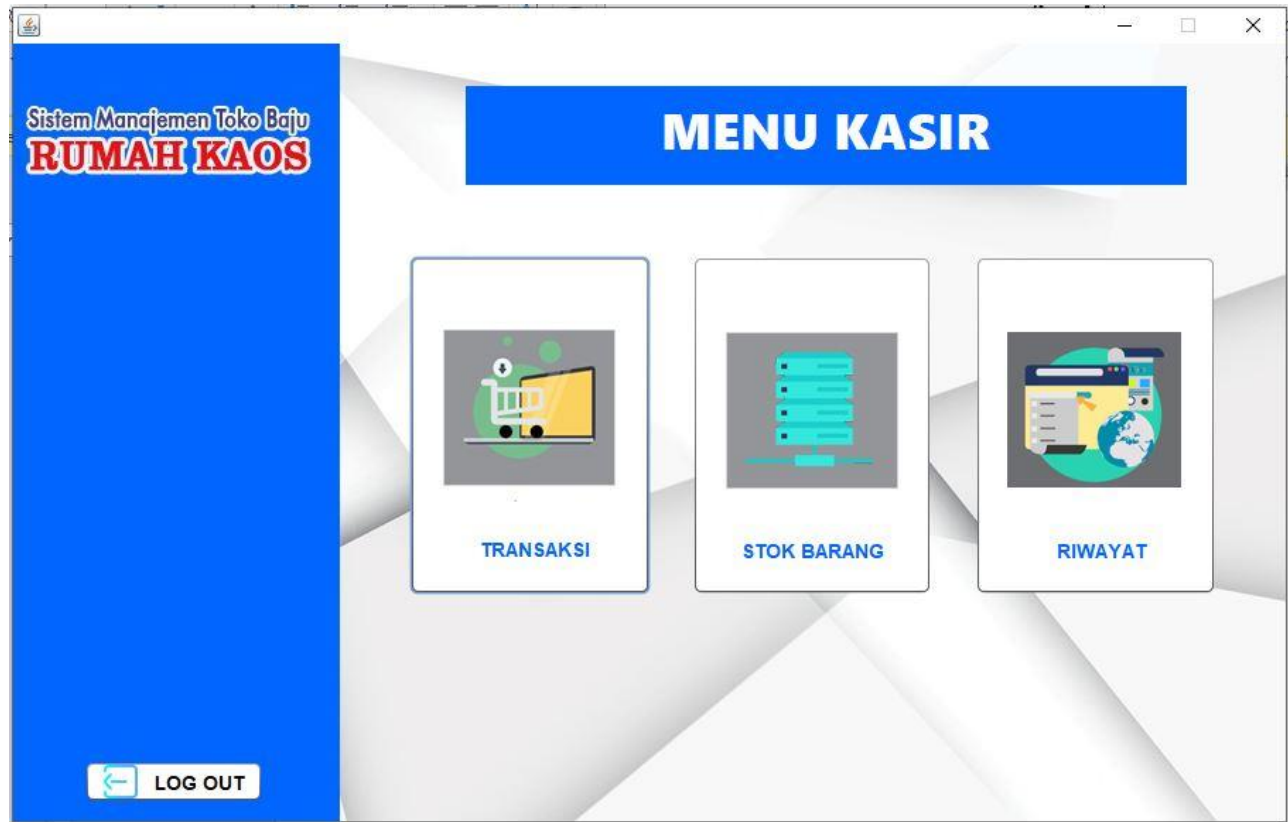

Gambar 6. Tampilan Layar Menu Kasir

Pada menu utama kasir terdapat beberapa menu yang akan menampilkan form transaksi, tabel stok barang, dan tabel riwayat.

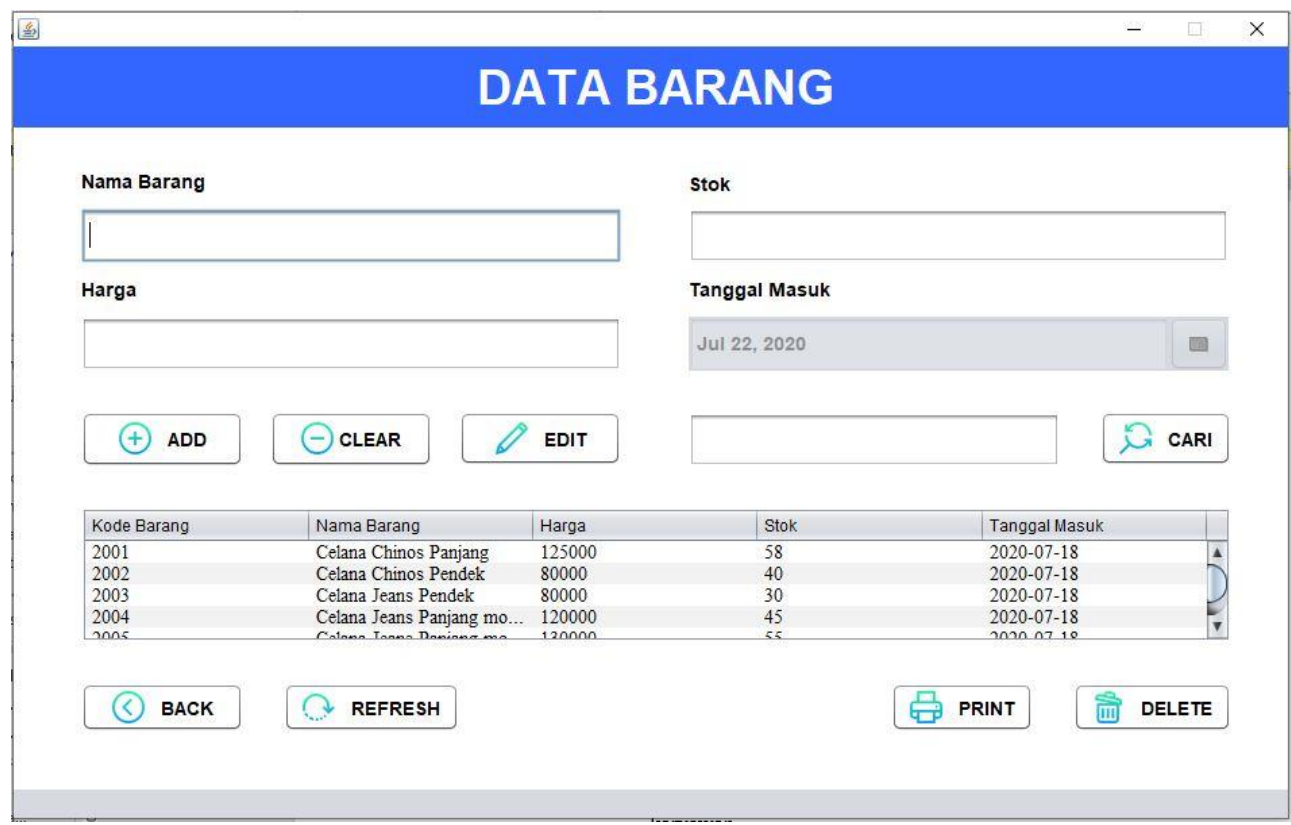

Gambar 7. Tampilan Layar Form Data Barang

Pada tampilan input data barang, barang yang masuk dari Supplier akan diinput kedalam form ini dan kemudian akan menghasilkan tabel barang. Data tersebut diisi sesuai dengan nama kolom yang sudah ada pada menu input data barang. Data yang sudah dimasukan oleh admin akan otomatis tersimpan di sistem. 


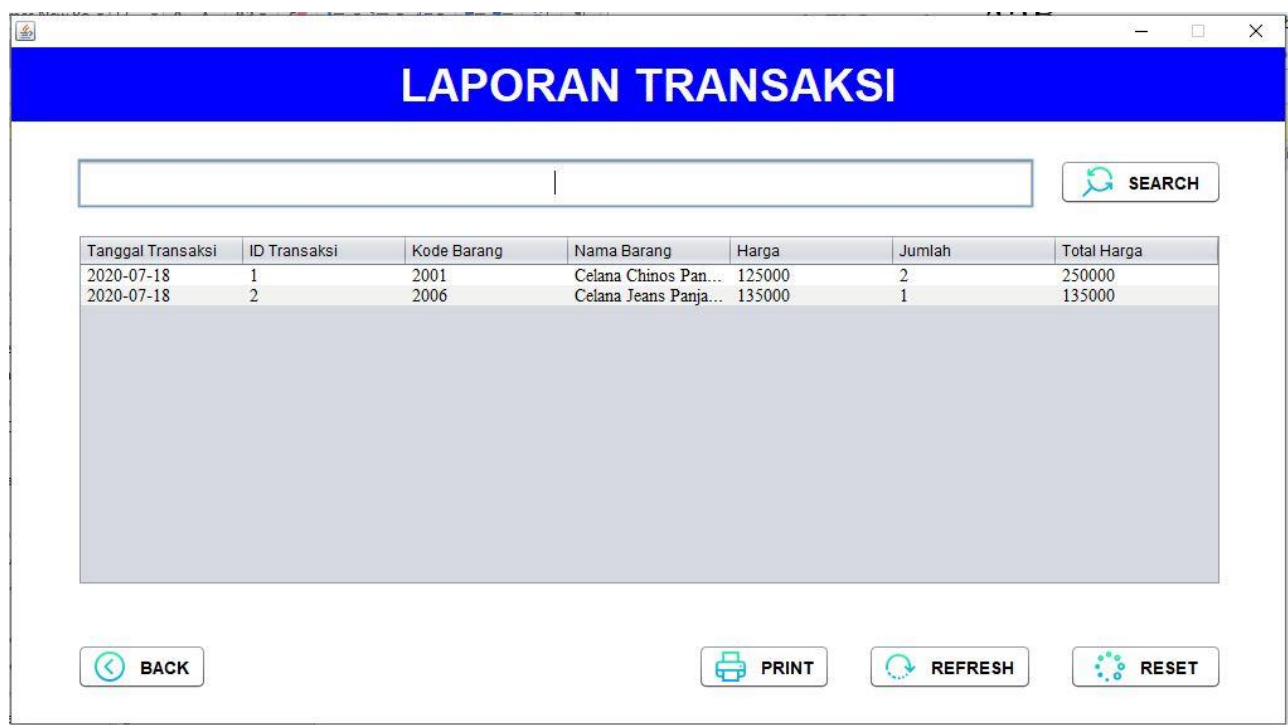

Gambar 8. Tampilan Layar Form Laporan Transaksi

Form ini digunakan oleh admin untuk menampikan data transaksi bedasarkan tabel transaksi .Form ini juga memudahkan dalan pencarian bedasarkan nama barang yang ada dalam transaksi. Kemudian ada menu print untuk mencetak laporan transaksi.

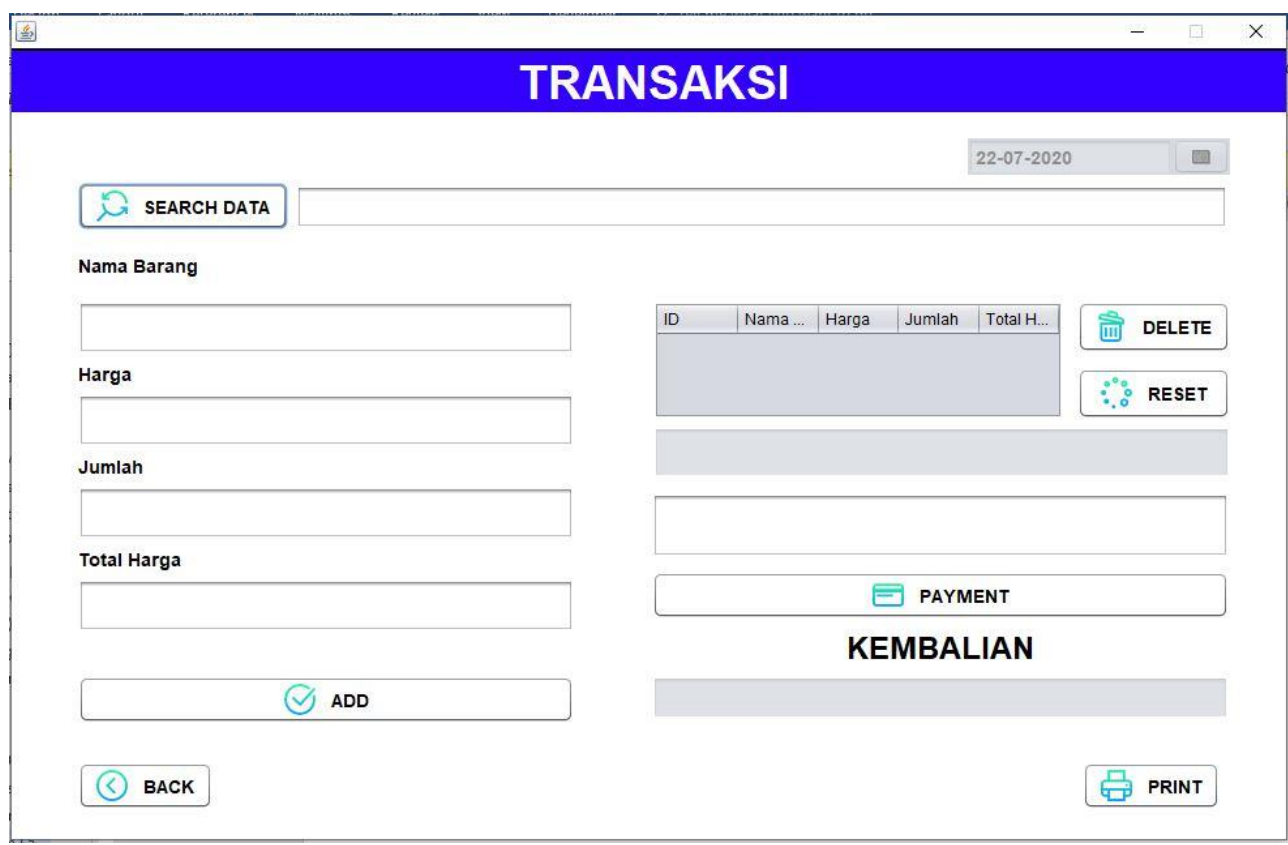

Gambar 9. Tampilan Layar Form Transaksi

Pada tampilan input transaksi, kasir mengisi data yang terdapat pada form. Data tersebut diisi sesuai dengan nama kolom yang sudah ada pada menu input. Data yang sudah dimasukan oleh admin akan masuk ke tabel keranjang. Serta data tersebut juga tersimpan di data transaksi. 


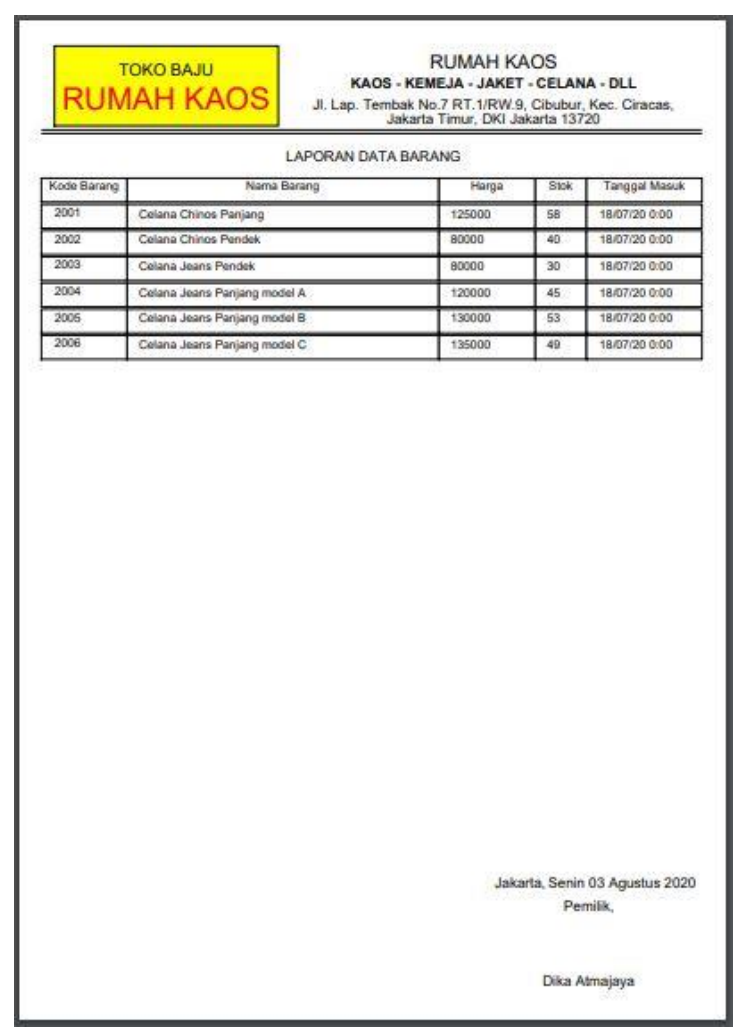

Gambar 10. Tampilan Format Laporan

Semua laporan pada apalikasi ini memiliki format yang sama yaitu kop dengan logo dan tulisan nama toko beserta alamat. Kemuadian ada judul laporan yang dicetak beserta data yang diperoleh dari database. Di samping bawah sebelah kanan terdapat Kota dan tanggal kemudian ada kolom tanda tangan pemilik agar dapat ditandatangai.

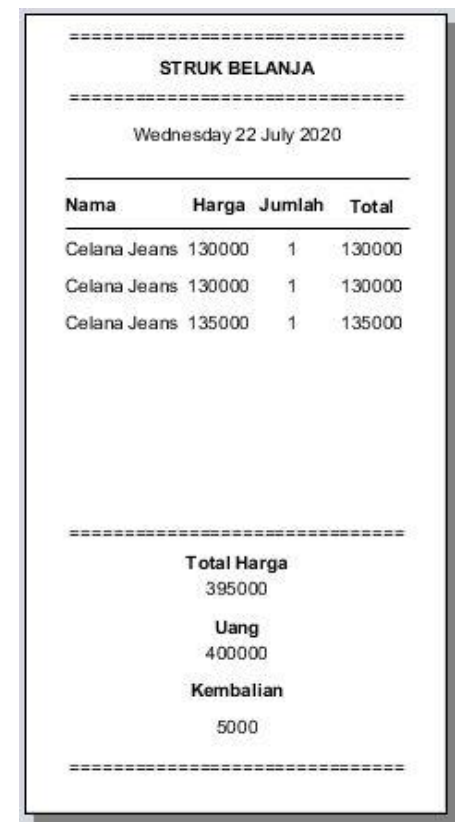

Gambar 11. Tampilan Struk Pembelian

Struk nota akan dicetak setiapkali ada transaksi. Struk ini besisi tanggal transaksi beserta barangbarang yang telah dibeli. Kemudian ada total harga, uang yang dibayarkan dan kembalian. 


\section{SIMPULAN}

Berdasarkan kegiatan penelitian yang sudah dilakukan peneliti selama perancangan hingga implementasi dan pengujian, maka dapat diambil kesimpulan yaitu dengan adanya sistem informasi manajemen ini, dapat memudahkan pemilik toko dan pembeli dalam mendapatkan informasi data barang yang dibutuhkan sehingga proses kegiatan penjualan menjadi lebih efektif dan efisien.

\section{DAFTAR PUSTAKA}

Ali, A. F. (2019). Rancang Bangun Aplikasi Penjualan Barang Berbasis Java Programming. Jurnal SIMTIKA Volume 2, No 1, Januari 2019.

Hasyim, Faisal Ibnu. (2012). Sistem Informasi Penjualan Pakaian Jadi Pada Distro Blindwear Bandung.

Herlina, H. (2016). Sistem Informasi Penjualan Pada Toko Busana Qiand Collection Berbasis Desktop. https://elib.unikom.ac.id/files/disk1/687/jbptunikompp-gdl-haniherlin-34342-1-unikom_h-1.pdf

Indrajani. (2011). Perancangan Basis Data Dalam all in 1. Jakarta: Elex Media Komputindo.

Kadir, A. (2014). Pengenalan Sistem Informasi Edisi Revisi. Yogyakarta: Andi.

Nofriadi. (2015). Java Fundamental dengan Netbeans 8.0.2. Yogyakarta: Deepublish.

O’Brien dan Marakas. (2013). Management Information Systems. Sixteenth Edition. New York: McGraw-Hill/Irwin. Pratini, Anggie. (2017). Perancangan Sistem Informasi Laporan Keuangan Pada Distro Viloci Pontianak.

Safroni, L. (2012). Manajemen dan Reformasi Pelayanan Publik dalam Konteks Birokrasi Indonesia. Surabaya: Aditya Media Publishing.

Wulandari, Anggreani P., dkk. (2018). Sistem Informasi Penjualan Pakaian Pada Butik Aulia. Jurnal Teknologi Terpadu Vol. 4, No. 2, Desember 2018. 